\title{
The System of Computer Modeling of Ash Cloud Propagation from Kamchatka Volcanoes
}

\author{
Aleksei Sorokin ${ }^{1}$, Olga Girina ${ }^{2}$, Sergei Korolev ${ }^{1+}$, Iraida Romanova ${ }^{2}$, Victor Efremov ${ }^{3}$, \\ Sergei Malkovskii ${ }^{1}$, Andrei Verkhoturov ${ }^{1}$ and Ivan Balashov ${ }^{3}$ \\ ${ }^{1}$ Computing Center, Far Eastern Branch, Russian Academy of Sciences, Khabarovsk, Russia \\ ${ }^{2}$ Institute of Volcanology and Seismology, Far Eastern Branch, Russian Academy of Sciences, \\ Petropavlovsk-Kamchatsky, Russia \\ ${ }^{3}$ Institute of Space Research, Russian Academy of Sciences, Moscow, Russia
}

\begin{abstract}
This paper describes the architecture, methods and technologies for implementation of the system of computer modeling of ash cloud propagation from Kamchatka volcanoes. The created system is part of an integrated software platform providing a joint analysis of the computer modeling results and satellite information in order to investigate volcanic activity.
\end{abstract}

Keywords: volcano, ash cloud, information system, model, puff, REST service, image.

\section{Introduction}

Explosive volcano eruptions are most hazardous in the world because of powerful energy release associated with volcanogenic process (catastrophic eruptions capable of releasing more than one cubic kilometre of ash and rising ash clouds as high as $30 \mathrm{~km}$ above sea level), and owing to their unpredictability. These eruptions threaten greatly the population and carry risks for the national economy, and, therefore, they need detailed investigation apart from the pure scientific interest. The topical problem is to develop the methods and systems for a comprehensive analysis of data obtained by different observation techniques aimed at studying and operative decision-making concerned with determination of the degree of danger of these natural hazardous events.

In recent decades, the development of observation methods (video- and satellite, in the first turn), associated with creation of new technologies for data processing and analysis [1,2], has provided converting qualitative information to quantitative information, which can be applied to investigate and describe various processes and phenomena including volcanic activity [3, 4].

Furthermore, the mathematical models such as PUFF [5], WRF-Chem [6], etc., using meteorological forecast data that allow calculating the ash plume trajectories, have become widely used in the world.

When working with different data types and technologies, and, also, using the experience of volcano eruption observations, it turns out possible to create the instrument for a comprehensive analysis of ash cloud and plume propagation from Kamchatka volcanoes. Such an instrument will allow increasing the validity of investigations in this research field.

Within the framework of the solution for the above problem, we have created the system of computer modelling of ash cloud propagation, and the services providing transmittance of the obtained results to specialized information systems to jointly operate with remote sensing data. The paper briefly describes the architecture of the created system and its operational principles.

${ }^{+}$Corresponding author. Tel.: + 79141965534; fax: +7(4212)227267.

E-mail address: serejk@febras.net. 


\section{Computer information system}

\subsection{Backlog for creation}

The key problem concerned with modelling the volcano ash cloud and plume trajectories consists in searching for the source of up-to-date expert information on the occurred eruption, and, also, recovering the necessary parameter values from it. The parameters describing a volcanic event include the eruption date and origin time, the plume height, etc.

The information on the above mentioned parameters for Kamchatka volcanoes is prepared and published by the researchers of KVERT team [7] in the form of VONA (Volcano Observatory Notification for Aviation) messages using the information system VOKKIA (Volcanoes of Kurile-Kamchatka Island Arc) [8], and is replicated to the automated information system (AIS) "Signal" [9], which enables facility management of the specialized instrumental observation network of the Far Eastern Branch of the Russian Academy of Sciences.

In order to make this information accessible in AIS "Signal", the data included in each VONA message are replicated in a special DBMS MySQL table "ash" associated with the reference table "volcanoes" (Fig. 1). Using statement-based replication built into MySQL, the content of the tables is transmitted to AIS "Signal” MySQL slave-server.

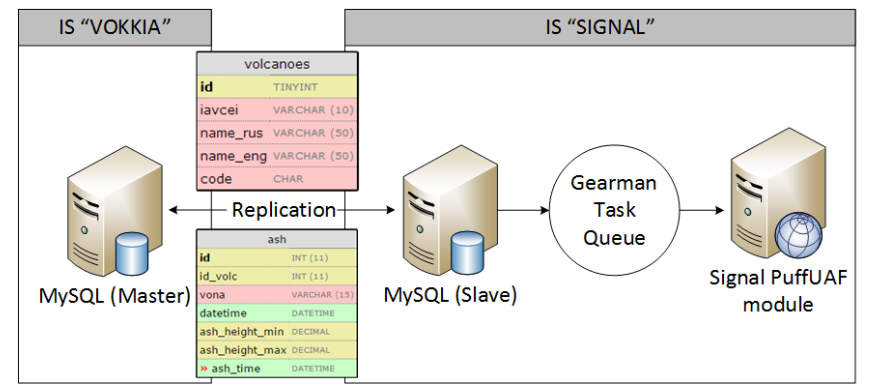

Fig. 1: A scheme showing the transmission of volcano eruption parameters to AIS "Signal".

The AFTERINSERT and AFTERUPDATE event triggers are adjusted to the table "ash" in AIS "Signal", which, after having received new data, transmit them to add_puff_task stored procedure assigned for publication of the received data as the task in the Gearman job server queue [10]. To do this, the appropriate specific UDF extension of MySQL server is used.

Preliminarily adjusted worker of AIS "Signal" takes the data from the queue, and the array of volcano eruption parameters becomes accessible for the computation modulus of the system, organized on the basis of the numerical PUFF model [5] and its puff-UAF software implementation [11].

\subsection{Numerical computations}

In order to perform computer calculations, we use the fields of zonal and meridional components of wind velocity (u- and v-components) at 26 pressure levels from 1000 to $10 \mathrm{mbar}$ covering the modelling area, as the auxiliary data. To organize the work with data, several subsystems are implemented which provide copying and synchronization of the actual local archive with forecast data (NCEP/NOAA, USA) and, also, a search for the optimal set of grib2 files to carry out modelling in relation to temporal data of the volcano eruption received from VONA message. These meteodata are transmitted to the program in the NetCDF format.

The received NetCDF file and the modelling parameters are used as the input values for the following run-time keys of the executed puff-UAF file:

- volc - volcano name;

- volcLat and volcLon - volcano coordinates;

- eruptDate - volcano eruption date and origin time (explosive event);

- plumeMin and plumeMax - minimum and maximum ash cloud height;

- eruptHours - volcano eruption duration time (the default time is set to 1 hour);

- runHours - the modeling period (the default time is set to 24 hours); 
- saveHours - the modeling interval (the default time is set to 2 hours);

- rcfile - configuration file with a description of NetCDF file of forecast meteodata.

After the program has been launched and executed, the files are formed with a description of the coordinates and heights of model particles of the ash cloud. The data of the above output files are used to form the resultant files containing the ash cloud trajectory in the format required (GIF, KML, PNG, etc.) (Fig. 2). The information about the performed automated computation, its parameters and obtained results is written down to a separate DBMS table, which is a reference table of the modelling results.

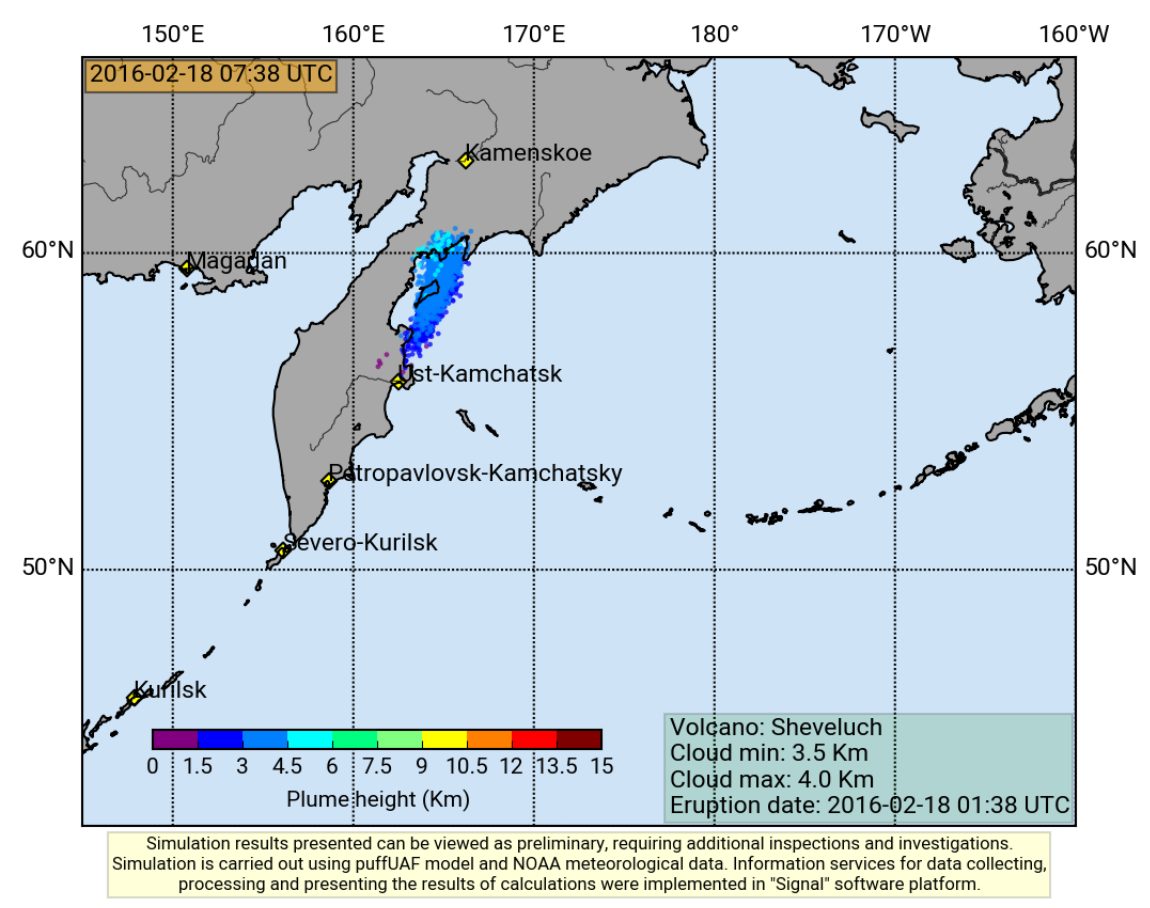

Fig. 2: An example showing a graphic file with modelling results.

\subsection{Organization of the information interaction}

The information system VolSatView [3] is the basic platform to carry out the joint analysis of ash plume propagation from volcanoes. In order for the results of the computational calculations, carried out in AIS "Signal", to be integrated into this system, we have created a web service providing the access to the reference table of the modelling results (Fig. 3).

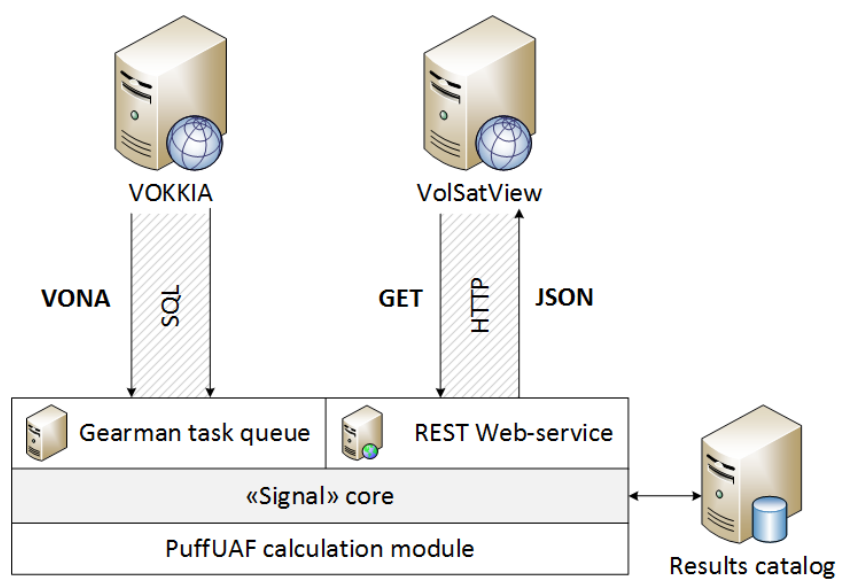

Fig. 3: A scheme showing the information interaction between the information systems.

The service has been created based on REST methodology; it operates on the basis of the HTTP(s) protocol. Using GET-query to VolSatView, the list of all performed calculations, including the parameter values and the obtained results, is downloaded encoded in the JSON format. 
Using the data contained in the list enables receiving and visualizing the modelling results of a concrete event, and carrying out a comparative analysis with the factual data obtained by remote sensing of the Earth from Space.

\section{Conclusion}

The analysis of ash cloud and plume propagation from volcanoes is a complicated interdisciplinary problem which requires different data types, technologies and software. It turns out extremely challenging to implement the necessary methods using exclusively a single platform. For this reason, the most effective approach suggests organizing the information interaction between the information systems and services, on whose basis the necessary competences are developed and specialized data archives are accumulated.

Based on this approach and involving the capabilities and resources of AIS "Signal", the information systems VOKKIA and VolSatView, the integrated software platform has been created which allows computer modelling of ash cloud and plume propagation from Kamchatka volcanoes and further joint analysis of the obtained calculation results and the satellite data.

\section{Acknowledgements}

This work was funded by the Russian Science Foundation (grant No. 16-17-00042).

\section{References}

[1] E.A. Loupian, A.A. Mazurov, R.R. Nazirov, et al. Technology of automated information system construction for satellite data acquisition, processing, storage and distribution to solve the scientific and applied problems. Modern problems of remote sensing of the Earth from Outer Space. 2004, 1: 81-88.

[2] V.Yu. Efremov, E.A. Loupian, A.A. Mazurov, et al. Technology of automated system construction for satellite data storage. Modern problems of remote sensing of the Earth from Outer Space. 2004, 1: 437-443.

[3] E.I. Gordeev, O.A. Girina, E.A. Loupian, et al. The study of eruption products of Kamchatka volcanoes using hyperspectral satellite data in the information system VolSatView. Modern problems of remote sensing of the Earth from Outer Space. 2015, 12 (1): 113-128.

[4] V.Yu. Efremov, O.A. Girina, L.S. Kramareva, et al. Creation of the information service "Remote Monitoring of Active Volcanoes of Kamchatka and the Kuril Islands". Modern problems of remote sensing of the Earth from Outer Space. 2012, 9 (5): 155-170.

[5] H.L. Tanaka. Development of a prediction scheme for volcanic ash fall from Redoubt volcano, Alaska. Proc. First International Symposium on Volcanic Ash and Aviation Safety. U.S. Geological Survey: Bulletin 2047. 1994, pp. 283-291.

[6] M. Stuefer, S. R. Freitas, G. Grell, et al. Inclusion of ash and SO2 emissions from volcanic eruptions in WRFChem: development and some applications. Geoscientific Model Development Discussions. 2012, 5 (3): 2571 2597.

[7] O.A. Girina, E.I. Gordeev. KVERT Project - aviation volcanic hazard mitigation during explosive eruptions of Kamchatka and North Kuril volcanoes. Bulletin of the Far Eastern Branch of the RAS. 2007, 2: 100-109.

[8] I.M. Romanova, O.A. Girina, A.P. Maksimov, I.V. Melekestsev. Creation of the complex information web-system "Volcanoes of the Kuril-Kamchatka Island Arc" (VOKKIA). Information science and managing systems. 2012, 3 (33): $179-187$.

[9] A.A. Sorokin, S.P. Korolev, I.P. Urmanov, et al. Software Platform for Observation Networks Instrumental Data Far Eastern Branch of the Russian Academy of Sciences. Proc. of International Conference on Computer Science and Environmental Engineering (CSEE 2015). Beijing. 2015, pp. 589-594.

[10] E. Day, B. Aker. The Gearman Cookbook. Open Source Convention. 2010, 7: p. 53.

[11] C. Searcy, K. Dean, W. Stringer. PUFF: a high-resolution volcanic ash tracking model. Journal of Volcanology and Geothermal Research. 1998, 80: 1-16. 